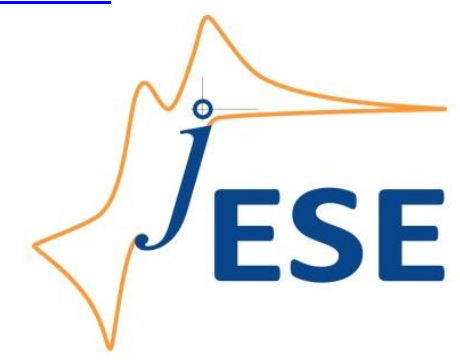

Open Access : : ISSN 1847-9286

www.jESE-online.org

Original scientific paper

\title{
Electrochemical behaviour and voltammetric determination of p-phenylenediamine at carbon paste electrode
}

\author{
Abdelaziz Ait Sidi Mou ${ }^{凶}$, Aicha Ouarzane, Mama El Rhazi \\ Laboratory of Physical Chemistry and Bioorganic Chemistry Mohammedia (FSTM), Morocco

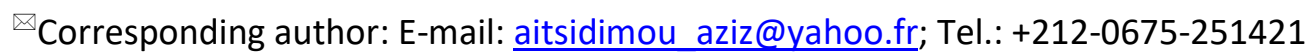

Received: April 18, 2017; Revised: June 26, 2017; Accepted: July 26, 2017

\begin{abstract}
An electrochemical method was developed for voltammetric determination of p-phenylenediamine using a carbon paste electrode (CPE). The electrode exhibited the highest electrocatalytic activity toward oxidation and reduction of $p$-phenylenediamine in the phosphate buffer, $\mathrm{pH}$ 7. After optimizing the experimental conditions and square wave voltammetry parameters, a linear current response toward concentration of $p$ phenylenediamine was obtained in the range of 0.12-3.00 $\mu \mathrm{M}$ with detection limit of $0.071 \mu \mathrm{M}$. The proposed procedure was successfully applied for determination of the total p-phenylenediamine content in the takeout extract sample.
\end{abstract}

\section{Keywords}

p-phenylenediamine; electroanalysis; voltammetry

\section{Introduction}

p-phenylenediamine ( $p-P D)$ is an aromatic diamine and derivative of the aniline with the chemical structure presented in Figure 1. It is commonly used in the manufacture of dyestuffs, as hair dye and as adjuvant of henna [1,2], in several industries, dyeing furs, photochemical processes, cosmetic and fabrication of household goods $[3,4]$. Toxic effects of $p-P D$, however, have also been reported by several authors [5-8].

Many analytical methods, including gas chromatography coupled mass spectrometry (GC-MS) $[9,10]$, gas chromatography (GC) [11], and high-performance liquid chromatography (HPLC) [2] have already been reported for the determination of $\mathrm{p}$-PD. Although chromatographic methods are sensitive and reliable, they have some disadvantages such as being time and labour consuming, expensive and demanding for sample pre-treatments and qualified personnel. Promising alternatives in this regard have been found in the electroanalytical methods which can offer high sensitivity, rapid response, easy operation and low cost [12]. 
Though the electrochemical properties of p-PD have been investigated at glassy carbon $[13,14]$ and carbon paste electrodes [15-18], most of these studies were mainly concerned on the mechanism of $p$-PD polymerization. Although several studies on the detection of some similar compounds in medical plants $[19,20]$ and drugs [21,22] were already published, the direct electroanalytical determination of $\mathrm{p}$-PD on carbon paste electrode has not been reported previously.

In this paper, we report on the electrochemical properties of p-PD on the surface of carbon paste electrode and this electrode will also be applied for the determination of $p$-PD content in the plant of takeout.<smiles>Nc1ccc(N)cc1</smiles>

Figure 1. Chemical structure of p-phenylenediamine

\section{Experimental}

\section{Apparatus}

Electrochemical experiments were carried out with an Autolab (Metrohm-Autolab, Utrecht Netherlands) PGSTAT302N potentiostat/galvanostat controlled by GPES 4.9 software. A threeelectrode electrochemical cell was employed for all electrochemical measurements. Carbon paste electrode (4 $\mathrm{mm}$ diameter) served as the working electrode, a platinum plate as the counter electrode, and $\mathrm{Ag} / \mathrm{AgCl}(3 \mathrm{~mol} / \mathrm{L} \mathrm{KCl}$ ) as the reference electrode, respectively. The $\mathrm{pH}$ of the buffer solutions was measured using a Fisher Scientific Accumet AB15 BASIC pH-meter.

\section{Reagents}

All chemicals used were of analytical grade. $\mathrm{P} \mathrm{p-PD}$ and graphite were purchased from Sigma and Fluka, respectively. Sodium hydroxide, $\mathrm{NaOH}, \mathrm{Na}_{2} \mathrm{HPO}_{4} \times 2 \mathrm{H}_{2} \mathrm{O}$ and $\mathrm{NaH}_{2} \mathrm{PO}_{4} \times 2 \mathrm{H}_{2} \mathrm{O}$ powders were purchased from Riedel-de Haën. All aqueous solutions were prepared in distilled water. The $\mathrm{pH}$ was adjusted with $\mathrm{NaOH}$. A p-PD stock solution of $1 \mathrm{mM}$ was prepared by dissolving $\mathrm{p}$-PD in the phosphate buffer solution (PBS) before use in measurements.

Preparation of the carbon paste electrode

The carbon paste electrode (CPE) was prepared by mixing $1 \mathrm{~g}$ of graphite powder and $0.3 \mathrm{~mL}$ of paraffin oil using a mortar and pestle until a homogenous paste was obtained. The paste was then incorporated into the electrode cavity ( $4 \mathrm{~mm}$ diameter) and polished by a smooth paper. Prior each measurement, the electrode surface was renewed.

\section{Sample preparation}

Takeout plant (Tamarix aphylla) samples were obtained from Zagora region, Morocco. The samples were firstly grounded by a crusher, then $1 \mathrm{~g}$ of the powder was weighed, dissolved in $50 \mathrm{~mL}$ of ethanol, and placed in a mounting reflux for $2 \mathrm{~h}$. After filtration, the solvent was evaporated by a rotavapor and an amount of the filtrate $(108 \mathrm{mg})$ was dissolved directly in $100 \mathrm{~mL}$ of $0.1 \mathrm{M}$ phosphate buffer solution (PBS), pH 7.0 for the final determination of the p-PD content. 


\section{Analytical procedure}

The electrochemical cell containing $1 \mathrm{mM}$ of p-PD dissolved in $0.1 \mathrm{M} \mathrm{PBS}, \mathrm{pH} 7.0$ was prepared. After that, the CPE electrode was placed in the test solution and the cyclic voltammetry was applied between -0.2 and $0.8 \mathrm{~V}$ at a scan rate of $50 \mathrm{mV} \mathrm{s}^{-1}$. The parameters of SWV of all measurements were, step potential $5 \mathrm{mV}$, amplitude $50 \mathrm{mV}$ and frequency $50 \mathrm{~Hz}$. The calibration curve of $\mathrm{p}-\mathrm{PD}$ concentrations was illustrated by SWV in the range of $0.12-3.0 \mu \mathrm{M}$ under the optimized conditions, and then used for directly determination to the amount of $p-P D$ in the sample of takeout extracts.

\section{Results and discussion}

\section{Electrochemical behaviour of p-phenylenediamine}

The electrochemical behaviour of $1 \mathrm{mM}$ p-PD on a CPE in the $0.1 \mathrm{M}, \mathrm{pH} 7.0$ PBS was investigated using cyclic voltammetry at a scan rate of $50 \mathrm{mV} \mathrm{s}^{-1}$. Whilst not any response is observed for the CPE in the blank solution (Fig. 2a), a pair of well-defined redox waves are observed in presence of $1 \mathrm{mM} \mathrm{p}$-PD in $0.1 \mathrm{M}, \mathrm{pH} 7 \mathrm{PBS}$ (Fig. 2b). The anodic, $E_{\mathrm{pa}}$, and cathodic, $E_{\mathrm{pc}}$, potentials are situated at $E_{\mathrm{pa}}=0.10 \mathrm{~V}$ and $E_{\mathrm{pc}}=0.03 \mathrm{~V}$, respectively. In general, presence of a peak in the reverse potential scan indicates reversibility of the oxidation process on the surface of the electrode.

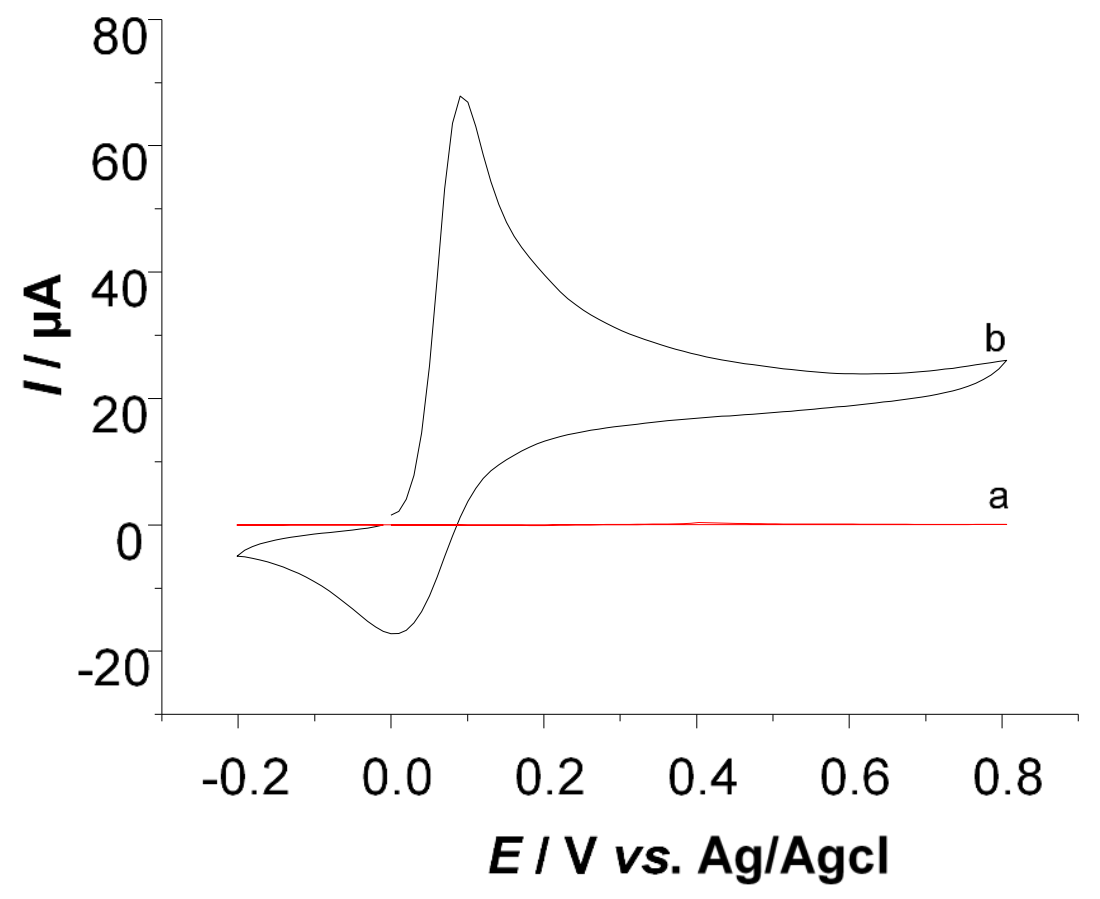

Figure 2. Cyclic voltammograms of CPE recorded at $50 \mathrm{mV} \mathrm{s}^{-1}$ in blank (a) and for $1 \mathrm{mM} p-P D$ in $0.1 \mathrm{M}$, pH 7.0 PBS (b).

The oxidation mechanism of p-phenylenediamine on the electrode surface

The redox reaction of $p$-PD belongs to a class of two-electron and two-proton processes [23]. Possible oxidation mechanism of $\mathrm{p}-\mathrm{PD}$ is shown in the Scheme 1 . After formation of radical cation from the amino group, electrons are delocalized over the cycle forming another cation from the second amino group, while by elimination of two protons, the oxidized P-PD is formed. The mesomeric effect of nitrogen atom plays an important role, and electron density increases at $\pi$-bond and hence oxidation becomes easy. 


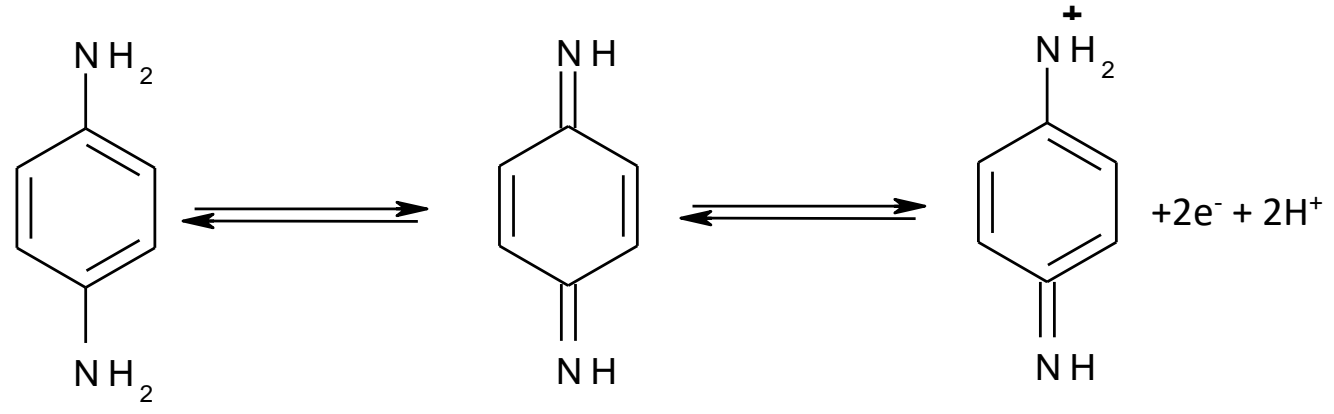

Scheme 1. The oxidation mechanism of p-phenylenediamine

\section{Effect of buffer $\mathrm{pH}$}

The effect of $\mathrm{pH}$ of the PBS on the electrochemical behaviour of $\mathrm{p}-\mathrm{PD}$ was studied in the $\mathrm{pH}$ range of 3.0-10.0. Fig. 3 shows that as $\mathrm{pH}$ value of the solution was increased, the redox peak is shifted negatively what indicates involvement of protons in the redox reaction [24]. Depending on a $\mathrm{pH}$ ranging from 3 to 7 , the formal potential $\left(E^{\circ}\right)$ for the anodic and cathodic peaks changed linearly. The redox current values increased from pH 3.0 and reached a maximum at pH 7.0 (curve $e$ in Fig. 3). Therefore, the PBS, pH 7.0 was selected as the optimum working solution which will offer a higher peak resolution of $\mathrm{p}-\mathrm{PD}$ and relatively higher current response.

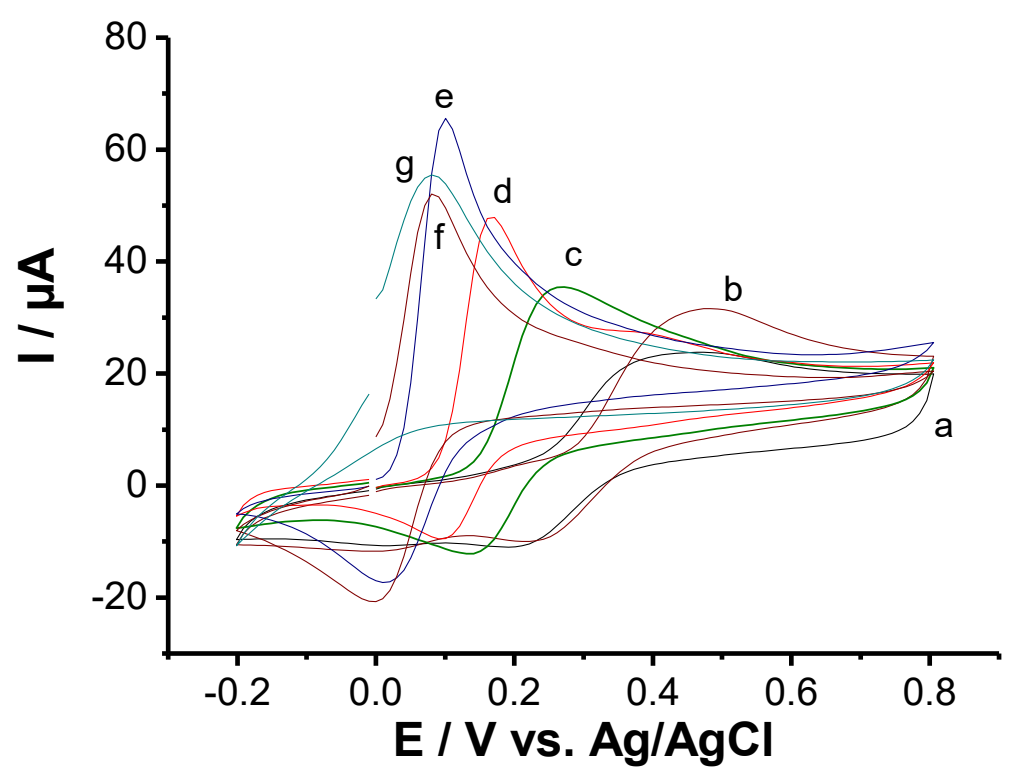

Figure 3. Cyclic voltammograms of CPE recorded at $50 \mathrm{mV} \mathrm{s}^{-1}$ for $1 \mathrm{mM} \mathrm{p}-\mathrm{PD}$ in PBS having $\mathrm{pH} 3-10$ : $a-3, b-4, c-5, d-d 6, e-7, f-8, g-10$.

\section{Effect of potential scan rate}

Fig. 4 shows the cyclic voltammograms of $\mathrm{p}-\mathrm{PD}$ at CPE in the PBS, $\mathrm{pH} 7.0$, recorded at the scan rates varied from 20 to $400 \mathrm{mV} \mathrm{s}^{-1}$. As is seen in the inset of Fig. 4, the redox peak currents at the $\mathrm{CPE}$ in the solution containing $\mathrm{p}-\mathrm{PD}$ increased linearly with the scan rate in the range from 50 to $250 \mathrm{mV} \mathrm{s}^{-1}$, what indicates the adsorption-controlled redox process. The linear regression equations can be defined as:

$$
\begin{aligned}
& I_{\mathrm{pa}} / \mu \mathrm{A}=71.76+0.36 u\left(\mathrm{mV} \mathrm{s}^{-1}\right)\left(\mathrm{R}^{2}=0.995\right) \\
& I_{\mathrm{pc}} / \mu \mathrm{A}=18.30-0.37 u\left(\mathrm{mV} \mathrm{s}^{-1}\right)\left(\mathrm{R}^{2}=0.996\right)
\end{aligned}
$$




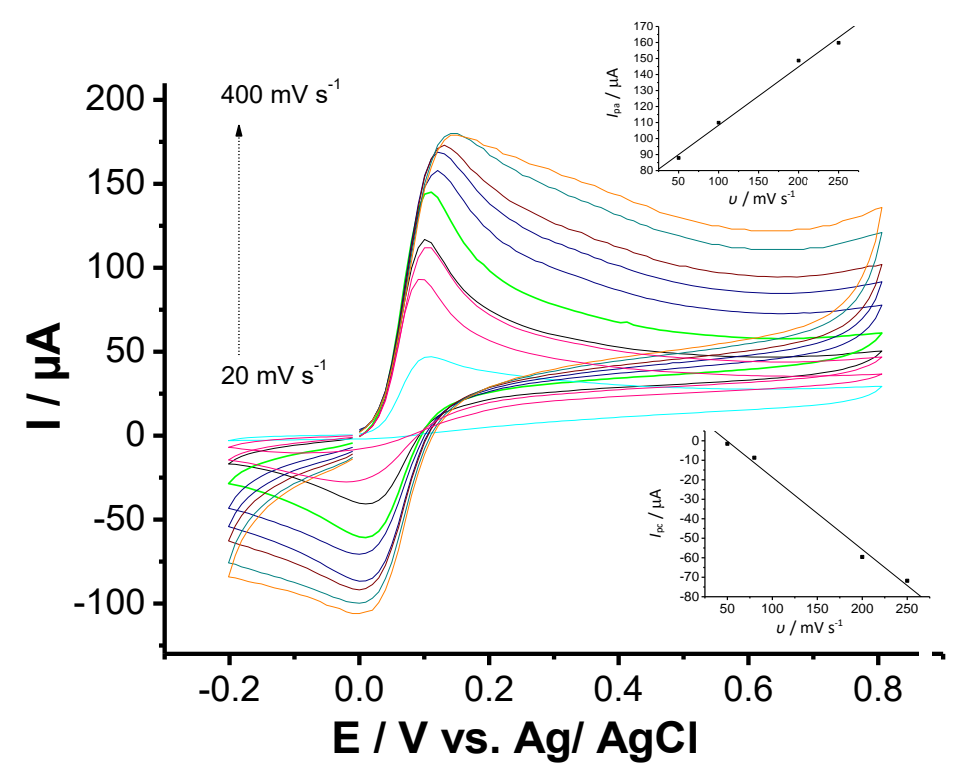

Figure 4. Cyclic Voltammograms of CPE for $1 \mathrm{mM}$ p-PD in PBS, $p H$ 7.0, recorded at scan rates $(U)$ of 20, 50, $80,100,150,200,250,300,350$ and $400 \mathrm{mV} \mathrm{s}^{-1}$. Inset: plots of peak currents (I $\mathrm{I}_{p a}$ and $\mathrm{I}_{p c}$ ) vs. scan rate (U) in the range from 50 to $250 \mathrm{mV} \mathrm{s}^{-1}$.

Effect of the square wave voltammetry (SWV) parameters and accumulation conditions

The effect of the accumulation potential in SWV measurements was investigated between $-0.2 \mathrm{~V}$ and $0.1 \mathrm{~V}$ at the accumulation time of $30 \mathrm{~s}$. As shown in Fig. 5A, the peak current values decreased significantly when the accumulation potential was shifted to potentials more positive than $-0.1 \mathrm{~V}$, because the p-PD adsorbed on the electrode becomes oxidized. Therefore, $-0.1 \mathrm{~V}$ was used as the accumulation potential. Similarly, the effect of accumulation time was studied in the 30-240 s range at the accumulation potential of $-0.1 \mathrm{~V}$. Fig. $5 \mathrm{~B}$ shows firstly a rapid increase in peak current values with increase of the accumulation time, then a maximum is reached at $120 \mathrm{~s}$ and after that, the constant values obtained indicate the saturation of the electrode surface by adsorbed layer. Therefore, $120 \mathrm{~s}$ was used as the proper accumulation time.
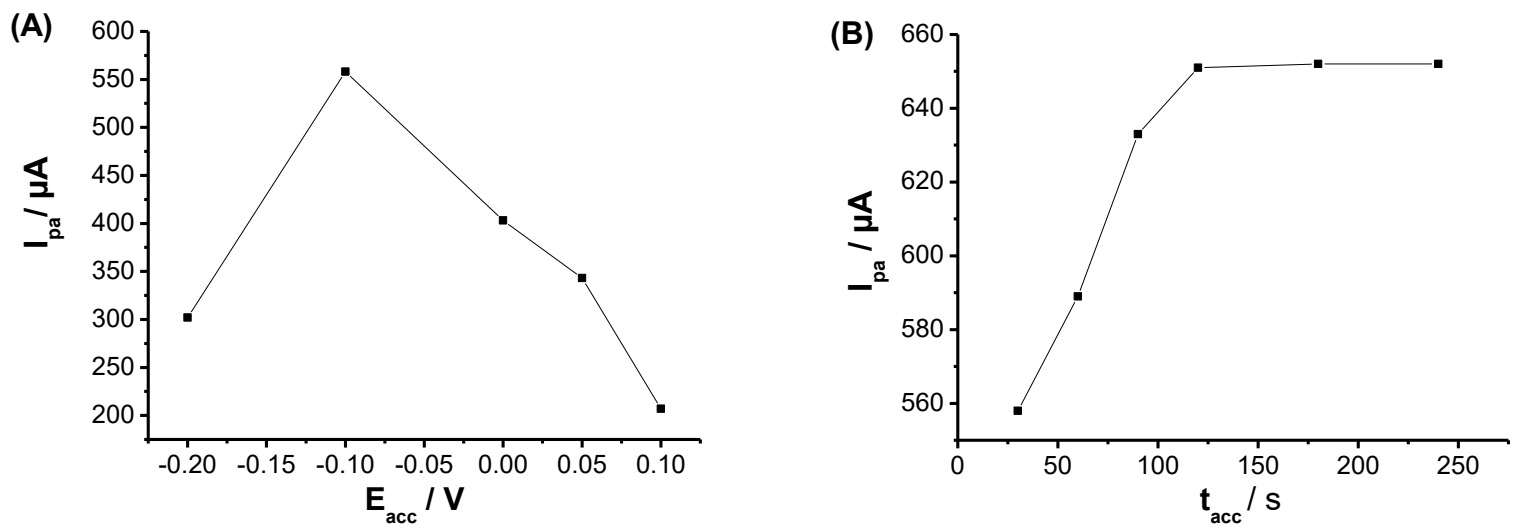

Figure 5. $\boldsymbol{A}$ - Effect of accumulation potential $(-0.2 \mathrm{~V}$ to $0.1 \mathrm{~V})$ to $I_{p a}$ values of $S W V$ responses measured for the accumulation time of $30 \mathrm{~s} ; \boldsymbol{B}$ - Effect of accumulation time (30 s to $240 \mathrm{~s}$ ) to $I_{p a} v a l u e s$ of SWV responses measured at the accumulation potential of $-0.1 \mathrm{~V}$.

\section{Calibration curve}

The relationship between the peak current and concentration of $\mathrm{p}-\mathrm{PD}$ was studied at the CPE by using SWV under the optimized conditions. Fig. 6 shows that the peak current values were linearly 
related to the concentration of $p-P D$ in the range of $0.12-3.0 \mu \mathrm{M}$. The linear regression equation was defined as: $I_{\mathrm{pa}} / \mu \mathrm{A}=0.181+0.241 \mathrm{C} / \mu \mathrm{M}$, with the correlation coefficient of 0.999 .

The detection limit calculated as $(3 \sigma / p)$ was $0.071 \mu \mathrm{M}$, where $\sigma$ and $p$ are the standard deviation of the blank and the slope of the calibration graph, respectively. The relative standard deviation (RSD) for repetitive measurements of $1.5 \mu \mathrm{M}$ p-PD was found to be $3.49 \%$ (five replicates), suggesting that the electrode demonstrated excellent repeatability.

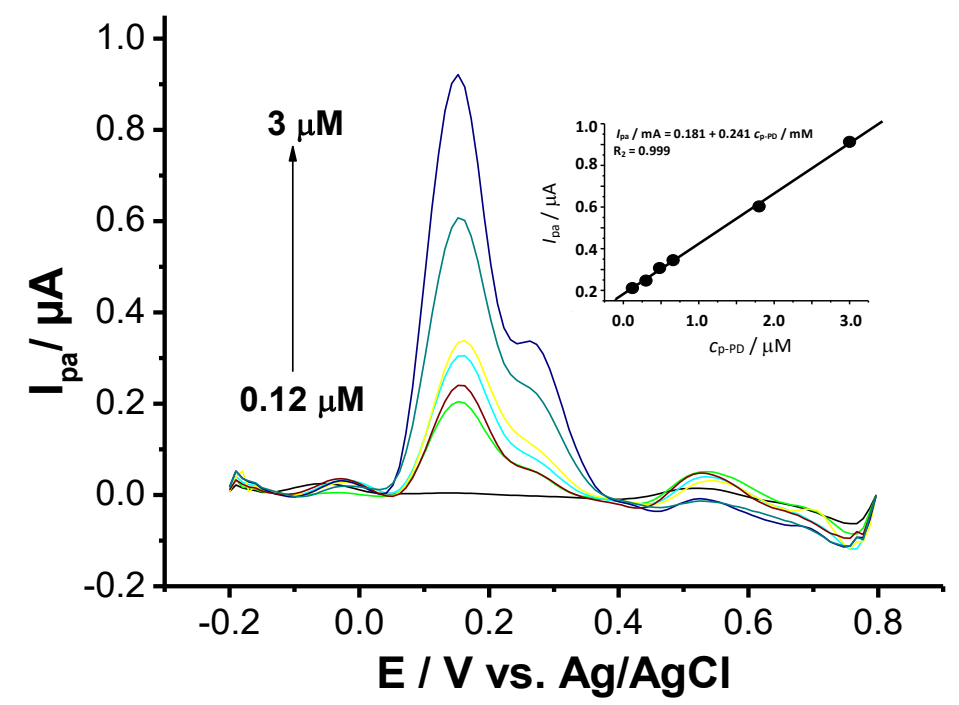

Figure 6. SWV responses of CPE in $0.1 \mathrm{M} P B S, p H 7.0$ and various concentrations of $p-P D$ in the range 0.12-3.0 $\mu \mathrm{M}$. Inset: linear calibration curve of peak current ( $\left.\mathrm{I}_{p a}\right)$ versus $p-P D$ concentration

\section{Interference study}

To evaluate possible interference of some foreign species on the determination of $p-P D, a$ systematic study was carried out. Data listed in Table 1 show the p-PD peak current ratios in the presence and absence of respective interferents. It seems that presence of $1.5 \mu \mathrm{M} \mathrm{Mg}^{2+}, \mathrm{K}^{+}, \mathrm{Na}^{+}$ and $\mathrm{Zn}^{2+}$ did not affect the determination of $\mathrm{p}$-PD. On the other hand, presence of $1.5 \mu \mathrm{M} \mathrm{Cu}{ }^{2+}$ showed a slight interference. In general, despite the high redox potential used for $\mathrm{p}$-PD detection, the interference study showed promising results for its selective determination.

Table 1. Effect of some foreign species on the peak current response of $0.3 \mu M p-P D$ in $P B S, p H 7$ at a fivefold concentration of interferent cations.

\begin{tabular}{cc}
\hline Interfering compound & Peak current ratio \\
\hline $\mathrm{Mg}^{2+}$ & 1.013 \\
$\mathrm{Zn}^{2+}$ & 0.760 \\
$\mathrm{~K}^{+}$ & 1.050 \\
$\mathrm{Na}^{+}$ & 1.050 \\
$\mathrm{Cu}^{2+}$ & 1.330 \\
\hline
\end{tabular}

\section{Analytical application}

The CPE was used to determine the amount of $\mathrm{p}-\mathrm{PD}$ in the takeout extracts. The results are shown in Table 2. Recovery measurements were made by adding known amounts of the standard $p-P D$ solution to the previously analyzed samples. The recovery for determination of p-PD was $110 \%$. The recovery indicated that the accuracy of the proposed method is acceptable. 
Following the sample preparation, measurements were performed similarly to those of standard p-PD solutions. The total $p$-PD contents were determined by using the former calibration curve equation. The total measured $\mathrm{p}$-PD content of the takeout sample $(\mathrm{w} / \mathrm{w})$ was determined as $1 \%$.

Table 2. Determination of $p-P D$ in plant takeout extract sample.

\begin{tabular}{lccccc}
\hline \multicolumn{5}{c}{ Amount of $p$-DP, $\mu \mathrm{M}$} & \multirow{2}{*}{ Recovery, \% } \\
\cline { 1 - 5 } Sample & Detected & Added & Expected & Found & \\
\hline Takaout extract & 0.54 & 1.5 & 2.04 & 2.25 & 110 \\
\hline
\end{tabular}

\section{Conclusions}

In this paper, a simple, rapid, and sensitive determination of $p$-phenylenediamine in the phosphate buffer solution, $\mathrm{pH} 7.0$ using the carbon paste electrode was proposed. A pair of welldefined redox peaks was obtained at the electrode. Under optimized conditions, the electrode showed excellent performance in terms of detection limit, linearity range, selectivity, repeatability, and recovery values. The proposed method was successfully applied for the determination of the total content of $p$-phenylenediamine in the plant of takeout sample.

\section{References}

[1] A. Ababou, K. Ababou, A. Mosadik, C. Lazreq, A. Sbihi, Annales Françaises d'Anesthésie et de Réanimation 19 (2000) 105-107.

[2] I. J. Kang, M. H. Lee, Contact dermatitis 55 (2006) 26-29.

[3] C. Mascres, J. Gaeton, L'union Medicale Du Canada 103 (1974) 672-677.

[4] K. S. Chugh, G. H. Malik, P. C. Singhal, Journal of Medicine 13 (1982) 131-137.

[5] A. Filali, I. Semlali, V. Ottaviano, C. Furnari, D. Corradini, R. Soulaymani, African Journal of Traditional, Complementary and Alternative Medicine 3 (2006) 142-149.

[6] S. Motaouakkil, B. Charra, A. Hachimi, H. Ezzouine, H. Guedari, H. Nejmi, A. Benslama, Annales Françaises d'Anesthésie et de Réanimation 25 (2006) 708-713.

[7] M. Abdelraheem, M. Hamdouk, E. E. Zijlstra, Arab Journal of Nephrology and Transplantation 3(1) (2010) 39-43.

[8] N. Habti, G. Benzakour, Y. Zaid, A. Naya, N. Nourichafi, H. Mifdal, S. Motaouakkil, M. Oudghiri, Journal of Toxicology and Environmental Health Sciences 2(7) (2010) 101-107.

[9] A.Stambouli, M. A. Bellimam, N. El Karni, T. Bouayoun, A. El Bouri, Forensic Science International 146S (2004) S87-S92.

[10] M. L. Di Gioia, A. Leggio, A. Le Pera, A. Liguori, A. Napoli, F. Perri, C. Siciliano, Journal of Chromatography A 1066 (2005) 143-148.

[11] S. Madi-Jebara, G. Sleilaty, A. Yazigi, Annales Françaises d'Anesthésie et de Réanimation 25 (2006) 902-910.

[12] A. Geto, M. Pita, A. L. De Lacey, M. Tessema, S. Admassie, Sensors and Actuators B 183 (2013) 96- 101.

[13] V. K. Gupta, M. L. Yola, N. Atar, Z. Ustundag, A. O. Solak, Electrochimica Acta 112 (2013) 541- 548.

[14] L. Zhang, Z. Shi, Q. Lang, J. Pan, Electrochimica Acta 55(3) (2010) 641-647.

[15] I. Adraoui, M. El Rhazi, A. Amine, L. Idrissi, A. Curulli, G. Palleschi, Electroanalysis 17(8) (2005) 685-693.

[16] A. Madhankumar, N. Rajendran, Synthetic Metals 162 (2012) 176- 185.

[17] B. Lakard, G. Herlem, S. Lakard, B. Fahys, Journal of Molecular Structure: THEOCHEM 638 (2003) 177-187. 
[18] M. Rani, R. Ramachandran, S. Kabilan, Synthetic Metals 160 (2010) 678-684.

[19] J. Li, J. Chen, X. L. Zhang, C. H. Lu, H. H. Yang, Talanta 83 (2010) 553-558.

[20] M. H. Parvin, Electrochemistry Communications 13 (2011) 366-369.

[21] X. Kang, J. Wang, H. Wu, J. Liu, I. A. Aksay, Y. Lin, Talanta 81 (2010) 754-759.

[22] M. Chao, X. Ma, X. Li, International Journal of Electrochemcal Science 7 (2012) 2201- 2213.

[23] S. A. da França, M. F. Dario, V. B. Esteves, A. R. Baby, M. V. R. Velasco, Journal of Cosmetics 2 (2015) 110-126.

[24] Q. Zheng, P. Yang, H. Xu, J. Liu, L. Jin, Journal of Environmental Sciences 24(9) (2012) 17171722.

(C)2017 by the authors; licensee IAPC, Zagreb, Croatia. This article is an open-access article distributed under the terms and conditions of the Creative Commons Attribution license (http://creativecommons.org/licenses/by/4.0/) 